\title{
Working
}

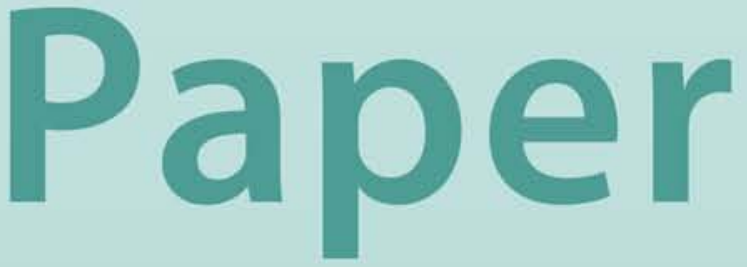


Welfare Effects of Transparency in Foreign Exchange Markets: The Role of Hedging Opportunities

Burkhard Drees and Bernhard Eckwert 


\title{
IMF Working Paper
}

\author{
International Capital Markets Department
}

\section{Welfare Effects of Transparency in Foreign Exchange Markets: The Role of Hedging Opportunities}

\author{
Prepared by Burkhard Drees ${ }^{1}$ and Bernhard Eckwert ${ }^{2}$ \\ Authorized for distribution by Garry J. Schinasi
}

December 2002

\begin{abstract}
The views expressed in this Working Paper are those of the author(s) and do not necessarily represent those of the IMF or MMF policy. Working Papers describe research in progress by the author(s) and are published to elicit comments and to further debate.
\end{abstract}

This paper studies the impact of enhanced transparency on risk sharing opportunities in the foreign exchange market and the associated implications for ex ante welfare. Transparency is measured in this model by the informational content of publicly observable signals about exchange rate developments. We find that in this model more transparency improves welfare in economies that are poorly endowed with capital and/or where investors are not very riskaverse, while welfare is reduced in economies with large capital endowments and/or where investors are highly risk-averse.

JEL Classification Numbers: D8, D51, D52

Keywords: Foreign exchange markets, information, transparency, hedging.

Authors’ E-Mail Addresses: bdrees@imf.org, beckwert@wiwi.uni-bielefeld.de

\footnotetext{
${ }^{1}$ International Capital Markets Department, International Monetary Fund, Washington, D.C., 20431, USA.

${ }^{2}$ Department of Economics, University of Bielefeld, D-33501 Bielefeld, Germany.
}

We thank in particular R. Todd Smith and Neil Wallace for valuable comments on an earlier version of this paper. Bernhard Eckwert gratefully acknowledges financial support from the Stifterverband für die Deutsche Wissenschaft and from Commerzbank. 


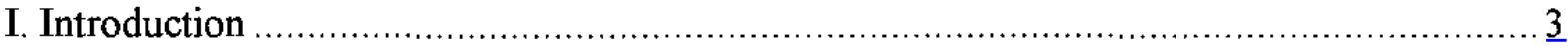

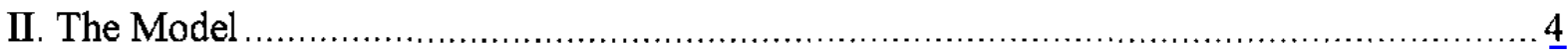

A. Consumption and Investment Decisions .................................................. $\frac{5}{\underline{5}}$

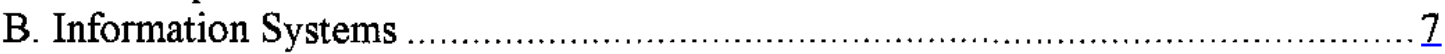

III. Welfare and Transparency in the Foreign Exchange Market .................................. $\underline{8}$

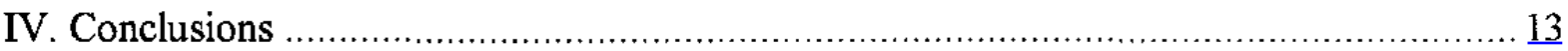

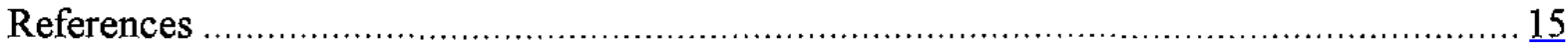




\section{INTRODUCTION}

The turbulence that swept through international currency markets in recent years convinced many economists that transparency in the global financial system needs to be strengthened. Transparency is generally understood as the availability of comprehensive information, for example, about the financial position of the government, the foreign exchange position of the central bank, the conditions of financial institutions, and fiscal and monetary policy more generally. By making more information available to help differentiate between risks, transparency is thought to promote the potential efficiency of markets and reduce uncertainty in the decision making of private market participants.

This paper investigates the implications of transparency with a more narrow focus: it identifies the effects of transparency on risk sharing opportunities and associated welfare implications. It does not model the standard benefits ascribed to transparency, such as the ability to differentiate better between good and bad risks and the related potential to exert a disciplining effect on public policies or private corporate policies. Based on a criterion that gauges the transparency of an economic environment, we analyze whether more transparency in the foreign exchange market is desirable from a welfare point of view in a partialequilibrium model of a small open economy. The key findings indicate that - under risk sharing aspects-more transparency in the foreign exchange market is not necessarily ex ante welfare-improving when agents can hedge the currency risk.

The notion of transparency adopted in this paper is linked to the informativeness of a signal that conveys some - though not perfect - information about the future spot exchange rate. The signal, which is observable by all agents, is imperfectly correlated with the future spot exchange rate. Specifically, the information contents of the signal (appropriately defined) will serve as a measure of transparency in this model: the more information is transmitted by the signal, the higher is the transparency of the foreign exchange market.

By the choice of the transparency criterion, this study is conceptually related to the literature that emerged from Blackwell's (1953) seminal work on the value of information. Comparing statistical experiments, Blackwell demonstrated that, in terms of expected utility, information always has positive value. However, Blackwell's analysis was based on the critical assumption that publicly observed information signals do not alter the economic environment in which agents are operating. Typically, this assumption is violated in equilibrium models where public information affects prices, risk premia, opportunity sets, etc. Early works by Drèze (1960) and Hirshleifer $(1971,1975)$ suggested that under special circumstances improved public information may reduce economic welfare by eliminating opportunities to reallocate risk through trade. The conditions under which information can be harmful in equilibrium models have been further investigated by Eckwert and Zilcha (2000; 2001), Green (1981), Orosel (1996), Schlee (2001), Sulganik and Zilcha (1996) and others. All these papers stress that the information structure of a market system can potentially interfere with the operation of risk sharing mechanisms. 
In the presence of risk sharing opportunities, better information has two opposing effects: (1) by anticipating the random state more reliably, agents can improve the quality of their decisions (Blackwell Effect); and (2) the more information is revealed, the more limited are the risk sharing opportunities (Hirshleifer Effect). In an economy with risk sharing mechanisms, the release of information may eliminate opportunities to reallocate risk through trade. As a result, agents may be worse off with better information from an ex ante point of view.

The key contribution of our paper is to present a model that combines aspects of the Blackwell and Hirshleifer environments and allows an assessment of transparency in the foreign exchange market. We derive parameter values (the degree of risk aversion and the size of the capital endowment) such that more transparency is welfare-improving, and values such that it is welfare-reducing in a model of a small open economy with stochastically fluctuating exchange rates. There are two types of agents: risk-averse investors who are endowed with capital and labor at date 0 , and firms that produce an output good using both labor and capital as inputs. At date 1, the production process is completed and the output is consumed. Capital can either be invested at home or abroad. The return (in domestic currency) of capital invested abroad is subject to exchange rate risk. The agents can hedge this risk by trading on a futures market. All consumers must make their investment decisions before the exchange rate uncertainty is resolved, but after they have observed a signal that is correlated with the random future exchange rate. Having observed the signal, agents revise their expectations and act according to their updated beliefs.

How does more transparency in the foreign exchange market (in the sense of more information being transmitted by the signal) affect the ex ante welfare of investors? It turns out that more transparency is welfare-improving (in a Pareto sense) in economies that are poorly endowed with capital (i.e., investors have a small exposure to foreign exchange risk) and/or where investors are less risk-averse. By contrast, in economies that are well endowed with capital and/or where investors are highly risk-averse, welfare declines as transparency increases. We also analyze the case where agents have no access to a currency futures market and hence are unable to hedge the currency risk. In such an economic environment, agents unambiguously benefit from more transparency in the foreign exchange market.

\section{THE MODEL}

Consider the partial equilibrium model of a small open economy which extends over two periods, $t=0,1$. The economy has homogeneous consumers/investors who are endowed with $I_{o}$ units of a commodity (capital) at date 0 . In both periods, the price of the commodity in the home currency is normalized to 1 . The commodity can be used for consumption, or it can be invested either at home or abroad. ${ }^{3} \mathrm{~A}$ unit of capital that is invested at home in period

\footnotetext{
${ }^{3}$ Below we will refer to this commodity as "capital," although it may be used for consumption as well.
} 
0 yields a return equal to $(1+r)$ in period 1 . Alternatively, capital goods can be sold to the foreign country with the proceeds being invested abroad. A unit of foreign currency invested at date $t=0$ yields a return of $\left(1+r^{*}\right)$ foreign currency units at date $t=1$. Thus, the return in domestic currency is $\left(e / e_{0}\right)\left(l+r^{*}\right)$, where $e$ denotes the random exchange rate at date $1, e_{0}$ is the exchange rate at date 0 (which is normalized to 1 ), and $r^{*}$ is the exogenous foreign rate of return on capital. The exchange rate $e$ is a random variable that assumes values in $\Omega:=[\underline{e}, \bar{e}]$ where $0<\underline{e}<\bar{e}<\infty$. Consumers live for two periods, they supply (inelastically) one unit of labor in the first period and consume in the second period.

As of date 0 , when the consumers make their investment decisions, the future exchange rate is random. However, prior to making their decisions, all agents observe a signal, $y$, which is correlated with the realization of the future exchange rate $e$. Thus the relevant expectation for $e$ is the updated posterior belief.

All agents have access to a futures market in which they can hedge their foreign exchange risk. A futures contract pays 1 unit of foreign currency at date 1 ; hence the payoff is worth $e$ units of domestic currency. We assume that risk-neutral arbitrageurs are active in the futures market, which implies that the futures market clears at the price $p(y)$ that is equal to the conditional mean of a contract's payoff,

$$
p(y)=E[e \mid y] .
$$

Both the payoff and the purchase price of the contract fall due in period 1.

\section{A. Consumption and Investment Decisions}

Each consumer maximizes expected utility, defined over random consumption. If $c$ is consumption, $s$ denotes investment at home and $h$ denotes sales (or purchases, if negative) in the currency futures market, the typical consumer chooses $s$ and $h$ such that:

$$
\begin{aligned}
& \max E[u(c)] \\
& \text { subject to } c=e\left(I_{0}-s\right)\left(I+r^{*}\right)+(I+r) s+w+h(p(y)-e),
\end{aligned}
$$

where $u$ is a strictly concave utility function, $E$ is the expectation operator conditional on information known at date 0 , and $w$ denotes the wage rate in domestic currency.

Aggregate domestic output is given by $F(K, L)$, where $K$ is the aggregate capital input and $L$ is the aggregate labor input. $F(K, L)$ is a neoclassical production function with constant returns to scale. It satisfies: $F_{K}(0, L)=\infty . F_{L}(K, 0)=\infty, F_{K}>0, F_{L}>0, F_{K K}<0$ and $F_{L L}<0$. Let $k=K / L$ and denote by $f(k)$ the per-capita production function. Given the above specifications, $f^{\prime}>0, f^{\prime \prime}<0$ and $f^{\prime}(0)=\infty$ holds. 
Firms maximize profits. In period 0 , they rent capital and hire labor in competitive domestic markets to produce a consumption good that will be available in period 1 . Foreign capital goods cannot be used in the domestic production process. Assuming that capital depreciates completely in the production process, the interest factor $(I+r)$ is given by the marginal product of capital, and the wage rate $w$ is equal to the marginal product of labor. In order to avoid corner solutions in problem (2), we assume

$$
f^{\prime}\left(I_{0}\right)<\underline{e}\left(l+r^{*}\right) .
$$

The timing of events in the economy is as follows:

$$
\text { date } 0
$$

date 1

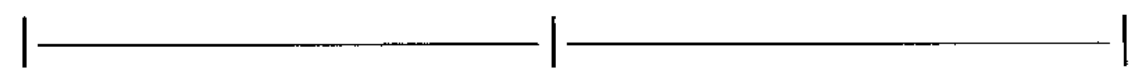

choice of information system; signal $y$ is observed; currency futures market opens; consumers choose portfolio $(s, h)$; firms choose $k$, exchange rate $e$ is realized; output is produced; factor income is paid; futures contracts are settled; consumption takes place.

Figure 1

A competitive equilibrium for this small open economy is defined as follows:

Definition 1 (competitive equilibrium) Given the per-capita initial endowment, $I_{0}$, and a realization of the signal, $y$, in period $0,[\hat{c}(e), \hat{s}, \hat{h}, \hat{r}, \hat{w}]$ is an equilibrium, if $\hat{s}, \hat{r}, \hat{w} \in I R_{+} ; \hat{h} \in I R ; \hat{c}(e)$ is a function defined on $\Omega$ into $I R_{+} ;$and

(i) given the interest rate $\hat{r}$ and wages $\hat{w}$, the consumers' utility optimum in problem (2) is attained at $[\hat{c}(e), \hat{s}, \hat{h}]$;

(ii) the aggregate capital stock at date 1 equals aggregate domestic investment at date 0 , i.e., $\hat{k}=\hat{s}$, where $\hat{k}$ is the per-capita capital at date $I$;

(iii) factor markets are competitive and clear:

$$
\begin{aligned}
1+\hat{r} & =f^{\prime}(\hat{k}) \\
\hat{w} & =\left[f(\hat{k})-\hat{k} f^{\prime}(\hat{k})\right] .
\end{aligned}
$$


The firms sell their products in the domestic market. Therefore, according to (4) and (5), the wage rate and the return on capital are not affected by the uncertain exchange rate at date 1 . Due to constant returns-to-scale in the production process, profits are equal to zero in equilibrium.

\section{B. Information Systems}

The uncertainty that agents face at date 1 arises from their lack of knowledge of the state variable $e \in \Omega$. Before choosing a portfolio at date 0 , they observe a signal $y \in Y \subset I R$, which is correlated with the future exchange rate. Thus the relevant expectation for $e$ is the updated posterior belief. An information system, denoted by $g$, specifies for each state of nature, $e$, a conditional probability function over the set of signals, $g(y \mid e)$. In other words, the positive real number $g(y \mid e)$ defines the conditional probability (density) that the signal $y$ will be observed if the true (yet unknown) state of nature is $e$. We assume that investors know the conditional probability function $g(y \mid e)$ by which the signals are generated. Using Bayes's rule, consumers revise their expectations and maximize utility on the basis of their updated beliefs.

Let $\pi: E \rightarrow I R_{+}$be the (Lebesgue) density function for the prior distribution over $\Omega$. The density for the prior distribution over $Y$ is given by

$$
v(y)=\int_{\Omega} g(y \mid e) \pi(e) d e \quad \text { for all } y .
$$

The density function for the updated posterior distribution over $\Omega$ is ${ }^{4}$

$$
v(e \mid y)=g(y \mid e) \pi(e) / v(y) .
$$

Following Blackwell (1953), a criterion can be defined that compares the information contents of different information systems. Suppose $g^{l}$ and $g^{2}$ are two information systems with associated density functions $v^{I}($.$) and v^{2}($.). The informativeness of an information system can be defined as follows:

Definition 2 (informativeness) $L e t g^{l}$ and $g^{2}$ be two information systems. The system $g^{l}$ is said to be more informative than $g^{2}$ (expressed by $g^{l} \succ_{\text {inf }} g^{2}$ ), if there exists an integrable function $\lambda: Y^{2} \rightarrow I R_{+}$such that

$$
\int_{Y} \lambda\left(y^{\prime}, y\right) d y^{\prime}=1
$$

\footnotetext{
${ }^{4}$ To avoid notational clutter, we distinguish between the functions $v(y)$ and $v(e \mid y)$ only by their arguments.
} 
holds for all $y$, and

$$
g^{2}\left(y^{\prime} \mid e\right)=\int_{Y} g^{1}(y \mid e) \lambda\left(y^{\prime}, y\right) d y
$$

holds for all $e \in \Omega .^{5}$

This concept of informativeness is based on a simple intuitive idea: the stochastic mechanism in equation (8) (the probability density $\lambda\left(y^{\prime}, y\right)$ ) transforms a signal $y$ into a new signal $y^{\prime}$. If the $y^{\prime}$-values are generated in this way, the new information system $g^{2}$ can be interpreted as being obtained from the information system $g^{l}$ by adding random noise.

To simplify the analysis, we will, however, use an alternative informativeness criterion that is equivalent to the condition stated in Definition 2.

Lemma 1 The information system $g^{l}$ is more informative than the information system $g^{2}$ if and only if

$$
\int_{Y} F\left(v^{1}(\cdot \mid y)\right) v^{1}(y) d y \geq \int_{Y} F\left(v^{2}(\mid y)\right) v^{2}(y) d y
$$

holds for every convex function $F($.$) on the set of density functions over \Omega$.

A proof of Lemma 1 can be found in Kihlstrom (1984). Note that $v^{I}(. \mid y)$ and $v^{2}(. \mid y)$ are the posterior beliefs under the two information systems. Thus, Lemma 1 implies that a more informative structure (weakly) raises the expectation of any convex function of posterior beliefs. If the function $F$ is concave, the inequality is reversed.

\section{Welfare AND TRANSPARENCY IN THE Foreign EXChange MARKeT}

We characterize an economic environment as more transparent, if risk is reduced through better information rather than through less economic uncertainty per se. In other words, transparency is modeled by the informational content of the signal: the foreign exchange market is said to be more transparent, if agents obtain more precise information about the future exchange rate, $e$, from observing the signal $y$.

Definition 3 Let $g^{l}$ and $g^{2}$ be two information systems for the exchange rate e. The foreign exchange market is said to be more transparent under $g^{l}$ than under $g^{2}$, if $g^{l} \succ_{\text {inf }} g^{2}$.

\footnotetext{
${ }^{5}$ By postulating that the function $\lambda$ must be integrable, we rule out the possibility that the two information systems are equally informative, i.e., that $g^{l} \succ_{\text {inf }} g^{2}$ and $g^{2} \succ_{\text {inf }} g^{l}$ holds.
} 
Now we turn to the question of how welfare in this economy is affected as the foreign exchange market becomes more transparent. Since the production technology exhibits constant returns-to-scale, no profits accrue from the production process. Similarly, speculation by risk-neutral arbitrageurs in the currency futures market yields zero average profits, since in equilibrium this market is unbiased. Moreover, because arbitrageurs are assumed to be risk-neutral, their expected utility does not depend on information. Thus firm owners and arbitrageurs can be neglected in the welfare analysis. By contrast, the economic welfare of investors is affected by the degree of transparency in the foreign exchange market.

Consider an information system $g$. Due to the strict concavity of the utility function, the optimal domestic investment, $s$, and futures market hedging, $h$, are determined uniquely by the first order conditions to problem (2):

$$
\begin{aligned}
& E\left[u^{\prime}\left(e\left(I_{0}-s\right)\left(1+r^{*}\right)+f(s)+h(p(y)-e)\right)\left[1+r-e\left(1+r^{*}\right)\right] \mid y\right]=0 \\
& E\left[u^{\prime}\left(e\left(I_{0}-s\right)\left(1+r^{*}\right)+f(s)+h(p(y)-e)\right)(p(y)-e) \mid y\right]=0, \quad(y \in Y)
\end{aligned}
$$

To derive (10) and (11), the market clearing factor prices from (4) and (5) have been used; as a result, $c=e\left(I_{0}-s\right)\left(I+r^{*}\right)+f(s)+h[p(y)-e]$. In view of (1), equation (11) implies $\operatorname{cov}\left(e, u^{\prime}(c)\right)=0$ and hence, due to the strict monotonicity of $u^{\prime}, h=\left(I_{0}-s\right)\left(1+r^{*}\right)$ and $c=p(y)\left(I_{0}-s\right)\left(I+r^{*}\right)+f(s)$ hold. Combining (10) and (11), and making use of (4), yields

$$
f^{\prime}(s)=p(y)\left(1+r^{*}\right)
$$

Denote by $s(p(y))$ the unique solution to (12) and define for any realization of the signal $y$ the value function $V(p(y))$ as the level of a typical consumer's expected utility,

$$
V(p(y)):=u\left(p(y)\left[I_{0}-s(p(y))\right]\left(1+r^{*}\right)+f(s(p(y)))\right) .
$$

Economic welfare, $W(g)$, is defined as the ex ante expected utility of the representative consumer prior to the realization of the signal,

$$
\begin{aligned}
W(g) & :=E_{y}[V(p(y))] \\
& =E_{y}\left[u\left(p(y)\left[I_{0}-s(p(y))\right]\left(1+r^{*}\right)+f(s(p(y)))\right)\right]
\end{aligned}
$$

More transparency in the foreign exchange market is beneficial, if consumers are better off with more precise information, i.e., if $W\left(g^{l}\right) \geq W\left(g^{2}\right)$ whenever $g^{l} \succ_{\text {inf }} g^{2}$.

In view of (1) and (12), optimal domestic investment is bounded from above by $\bar{s}$ and from below by $\underline{s}$, where the constants $\bar{s}, \underline{s}$ are implicitly defined by 


$$
\begin{aligned}
& f^{\prime}(\underline{s})=\bar{e}\left(1+r^{*}\right) \\
& f^{\prime}(\bar{s})=\underline{e}\left(1+r^{*}\right) .
\end{aligned}
$$

Comparing (3) and (12) shows that $\bar{s}<I_{0}$, i.e., the agent's capital investment abroad, $I_{0}-s$, is strictly positive. Let

$$
\begin{aligned}
\bar{f}^{\prime \prime} & :=\max _{\underline{s} \leq s \leq \bar{s}} f^{\prime \prime}(s) \\
\underline{f}^{\prime \prime} & =\min _{\underline{s} \leq s \leq \bar{s}} f^{\prime \prime}(s) .
\end{aligned}
$$

Note that $\underline{s}, \bar{s}, \bar{f}^{\prime \prime}, \underline{f}^{\prime \prime}$ are independent of $I_{O}$

Finally, let $\gamma(c):=-\frac{u^{\prime \prime}(c)}{u^{\prime}(c)}$ be the measure of absolute risk aversion, and define

$$
\begin{aligned}
& A\left(I_{0}\right):=\frac{-1}{\left(I_{0}-\bar{s}\right)^{2} \bar{f}^{\prime \prime}} \\
& B\left(I_{0}\right):=\frac{-1}{\left(I_{0}-\underline{s}\right)^{2} \underline{f}^{\prime \prime}} .
\end{aligned}
$$

Clearly, $A\left(I_{0}\right) \geq B\left(I_{0}\right)$. Now one of the key results of the paper can be stated:

Theorem 1 Let $g^{2}$ and $g^{2}$ be two information systems such that the foreign exchange market is more transparent under $g^{l}$ than under $g^{2}$.

(i) Economic welfare is higher under $g^{1}$ than under $g^{2}$, if the measure of absolute risk aversion, $\gamma(c)$, is smaller than or equal to $B\left(I_{0}\right)$.

(ii) Economic welfare is higher under $g^{2}$ than under $g^{2}$, if the measure of absolute risk aversion, $\gamma(c)$, is greater than or equal to $A\left(I_{0}\right)$.

Proof: In view of Lemma 1, we have to show that the value function in (13) is convex in the updated posterior belief $v(e \mid y)$ under the condition stated in (i), and that the value function is concave in $v(e \mid y)$ under the condition stated in (ii). Since $p(y):=E[e \mid y]$ is linear in the posterior belief $v(e \mid y)$, the value function will be convex (concave) in $v(e \mid y)$ if it is convex (concave) in $p(y)$. Differentiating (13) with respect to $p(y)$ and taking (12) into account, we arrive at 


$$
\begin{aligned}
V^{\prime \prime} & =u^{\prime \prime}\left[\left(I_{0}-s\right)\left(1+r^{*}\right)\right]^{2}+u^{\prime}\left[-2 s^{\prime}\left(1+r^{*}\right)+f^{\prime \prime} \xi^{2}\right] \\
& =u^{\prime \prime}\left[\left(I_{0}-s\right)\left(1+r^{*}\right)\right]^{2}-u^{\prime}\left[\left(1+r^{*} *\right)^{2} / f^{\prime \prime}\right] \\
& =u^{\prime \prime}\left[I_{0}-s\right]^{2}\left(1+r^{*}\right)^{2}\left[-\gamma-\frac{1}{f^{\prime \prime}\left[I_{0}-s\right]^{2}}\right] .
\end{aligned}
$$

Clearly, $V^{\prime \prime}(\cdot) \geq 0$ if $\gamma(c) \leq B\left(I_{0}\right), \forall c$; and $V^{\prime \prime}(\cdot) \leq 0$ if $\gamma(c) \geq A\left(I_{0}\right), \forall c$.

Q.E.D.

Note that $A\left(I_{0}\right)$ converges to zero, if $I_{0}$ tends to infinity. Thus according to (ii) in Theorem 1, more transparency in the foreign exchange market causes welfare losses if the initial endowment is sufficiently high and/or relative risk aversion is sufficiently high. Conversely, according to (i) in Theorem 1, more transparency is beneficial if the initial endowment is low and/or relative risk aversion is low.

These results are driven by the interaction between the Blackwell Effect and the Hirshleifer Effect. ${ }^{6}$ The Blackwell Effect captures the increase in economic welfare that results from the fact that agents make better decisions if they act in a more transparent (i.e., less uncertain) economic environment. By contrast, the Hirshleifer Effect captures the welfare losses that result from the elimination of risk hedging opportunities that goes handin-hand with more transparency: the currency futures market allows agents to hedge that part of the foreign exchange risk that has not yet been resolved by the signal. Thus, the more informative is the signal, the smaller is the portion of the foreign exchange risk that can be hedged. This effect may translate higher transparency in the foreign exchange market into lower economic welfare.

The welfare loss that is caused by the destruction of hedging opportunities is larger the more risk-averse investors are. However, the welfare loss also depends on the currency risk exposure, $I_{0}-s$; i.e., the investment in the foreign capital market that is exposed to exchange rate risk. If the risk exposure is small, the loss of risk sharing opportunities due to more informative signals will only have a minor impact on economic welfare. If, however, $I_{0}$ is large and, hence, the risk exposure is large, ${ }^{7}$ the loss of hedging opportunities will have a strong negative impact on welfare.

\footnotetext{
${ }^{6}$ This interaction has recently been studied by Eckwert and Zilcha (2000) in a general equilibrium context of a closed economy (see also Hakansson and others, 1982; and Schlee, 2001).
}

${ }^{7}$ Recall that investment at home, $s$, does not depend on $I_{0}$ (see equation (12)). 
Summarizing, the Hirshleifer Effect depends on the attitudes toward risk and on the risk exposure of investors. If investors are highly risk-averse and/or if their risk exposure is high, the Hirshleifer Effect dominates the Blackwell Effect and, hence, more transparency is undesirable.

The Hirshleifer Effect does not exist in a market system where no risk-hedging instruments are available. Thus, in the absence of futures markets, economic welfare increases unambiguously with more transparency in the foreign exchange market. This result is stated formally in the next theorem.

Theorem 2 Let $g^{l}$ and $g^{2}$ be two information systems such that the foreign exchange market is more transparent under $g^{1}$ than under $g^{2}$. If the foreign currency cannot be traded in a futures market at date 0 , economic welfare is higher under $g^{l}$ than under $g^{2}$.

Proof: In the absence of a futures market, the first-order condition for a consumer's decision problem reads

$$
E\left[u^{\prime}\left(e\left(I_{0}-s\right)\left(1+r^{*}\right)+f(s)\right)\left[1+r-e\left(1+r^{*}\right)\right] \mid y\right]=0, \quad(y \in Y) .
$$

Denote the unique solution to (19) by $s(y)$ and define

$$
U(s(y), e):=u\left(e\left(I_{0}-s(y)\right)\left(1+r^{*}\right)+f(s(y))\right) .
$$

The value function is

$$
V(v(\mid y))=\int_{\Omega} U(s(y), e) v(e \mid y) d e .
$$

We show that the value function is convex in the posterior belief $v(\cdot \mid y)$. Assume $v(\cdot \mid y)=$ $\alpha v^{l}(\cdot \mid y)+(I-\alpha) v^{2}(\cdot \mid y), \alpha \in[0, I]$, and denote by $s^{l}(y)$ and $s^{2}(y)$ the optimal investment in the home country under the posterior beliefs $v^{l}(\cdot \mid y)$ and $v^{2}(\cdot \mid y)$, respectively. We obtain

$$
\begin{aligned}
V(v(\cdot y)) & =\int_{\Omega} U(s(y), e)\left[\alpha v^{1}(e \mid y)+(1-\alpha) v^{2}(e \mid y)\right] d e \\
& \left.=\alpha \int_{\Omega} U(s(y), e) v^{1}(e \mid y) d e+(1-\alpha) \int_{\Omega} U(s(y), e) v^{2}(e \mid y)\right] d e \\
& \left.\leq \alpha \int_{\Omega} U\left(s^{1}(y), e\right) v^{1}(e \mid y) d e+(1-\alpha) \int_{\Omega} U\left(s^{2}(y), e\right) v^{2}(e \mid y)\right] d e \\
& =\alpha V\left(v^{1}(\mid y)\right)+(1-\alpha) V\left(v^{2}(\cdot \mid y)\right) .
\end{aligned}
$$

The inequality holds because $s^{l}(y)$ and $s^{2}(y)$ maximize expected utility if the posterior belief is given by $v^{I}(. \mid y)$ and $v^{2}(\cdot \mid y)$, respectively. 
We have shown that the value function is convex in the posterior beliefs. Now the claim in Theorem 2 follows from Lemma 1.

Q.E.D.

Theorem 2 captures the direct welfare effect resulting from market transparency: since, by assumption, currency risk cannot be hedged, the risk allocation remains unaffected when the foreign exchange market becomes more transparent. All agents benefit from better transparency because their exposure to economic uncertainty is lower at the time when they make their consumption and investment decisions.

Things are different if currency risk can be hedged. While the direct effect continues to be operative, also an indirect welfare effect emerges: more transparency destroys risk sharing opportunities and thereby imposes welfare costs on risk-averse investors. If investors are strongly risk-averse, the adverse indirect welfare effect dominates the favorable direct welfare effect and overall welfare decreases with more market transparency.

The normative implications of this model thus depend on the risk hedging opportunities available in the foreign exchange market. If agents do not have access to hedging instruments, foreign exchange markets should be as transparent as possible since in this case enhanced transparency implies unambiguously higher economic welfare. Yet, in view of Theorem 1, market transparency appears to be less important, or may even be undesirable, if financial instruments exist that offer protection against exchange rate fluctuations. In fact, well-developed risk sharing markets can be viewed as effective tools for mitigating allocational inefficiencies that may otherwise result from a lack of transparency.

\section{Conclusions}

This paper proposes a theoretical concept of market transparency where the negative Hirshleifer Effect and the positive Blackwell Effect can be studied in combination. The interaction of these two effects is found to be critical for an assessment of the economic effects of better market transparency. Our analysis shows that more transparency in the foreign exchange market is not necessarily desirable when agents are able to hedge their currency risk. If the economy is well endowed with capital and/or investors are highly riskaverse, more transparency makes all agents worse off. Both high risk aversion and high capital endowments strengthen the Hirshleifer Effect: with high risk aversion, agents are more severely affected when risk sharing opportunities are eliminated through better market transparency. Large capital endowments increase the risk exposure of investors, leaving them more vulnerable to the loss of risk sharing opportunities. By contrast, more transparency unambiguously improves welfare in an economic environment without hedging opportunities for currency risk.

The notion of transparency adopted in this paper is a special one. Transparency in the foreign exchange market is linked to the informativeness of a publicly observable signal for the future spot exchange rate. While, in our view, this approach has intuitive appeal, alternative concepts of transparency, which typically include some notion of information 
asymmetry, may lead to different results. For example, much of the literature initiated by Grossman and Stiglitz (1976) uses a transparency concept that applies to endogenous signals and measures the amount of private information that is conveyed through trading. In this literature, transparency is defined by means of the signal-to-noise ratio. A higher signal-tonoise ratio indicates that more private information has been incorporated into market prices. Thus in Grossman-Stiglitz type models, this criterion measures the informativeness of endogenous price signals. If restricted to exogenous signals, the criterion is formally equivalent to our transparency concept in the sense of Blackwell (Grossman and Stiglitz, 1980; and Grossman, Kihlstrom, and Mirman, 1977).

Although the fundamental factors that drive exchange rates are not modeled in this partial equilibrium setting, the thrust of our analysis applies more generally. Since no restrictions are imposed on the distribution of the random exchange rate, it should be possible, in principle, to embed our model into a general equilibrium approach where the stochastic process of the exchange rate is derived endogenously. The key mechanisms that produce the main results in this paper would equally apply in such a general equilibrium model. 


\section{REFERENCES}

Blackwell, David, 1953, "Equivalent Comparison of Experiments," Annals of Mathematics and Statistics, Vol. 24, pp. 265-72.

Drèze, Jacques H., 1960, "Le paradoxe de l'information," Economie appliquée, Vol.13, pp. 71-80.

Eckwert, Bernhard, and Itzhak Zilcha, 2000, "Incomplete Risk Sharing Arrangements and the Value of Information," working paper, Foerder Institute for Economic Research, Tel Aviv University, forthcoming in: Economic Theory.

, 2001, "The Value of Information in Production Economies," Journal of Economic Theory, Vol. 100, No. 1, pp. 172-86.

Green, Jerry, 1981, "The Value of Information with Sequential Futures Markets," Econometrica, Vol. 49, pp. 335-58.

Grossman, Sanford J., Richard E. Kihlstrom and Leonard J. Mirman, 1977, "A Bayesian Approach to the Production of Information and Learning by Doing," Review of Economic Studies, Vol. 64, pp. 533-47.

Grossman, Sanford J., and Joseph Stiglitz, 1976, "Information and Competitive Price Systems," American Economic Review, Vol. 66, pp. 246-53.

__. 1980, "On the Impossibility of Informationally Efficient Markets," American Economic Review, Vol. 70, pp. 393-408.

Hakansson, Niels H., Gregory Kunkel and James A. Ohlson, 1982, "Sufficient and Necessary Conditions for Information to Have Social Value in Pure Exchange," Journal of Finance, Vol. 37, pp. 1169-81.

Hirshleifer, Jack, 1971, "The Private and Social Value of Information and the Reward to Incentive Activity," American Economic Review, Vol. 61, pp. 561-74.

___ , 1975,"Speculation and Equilibrium: Information, Risk and Markets," Quarterly Journal of Economics, Vol. 89, pp. 519-42.

Kihlstrom, Richard E., 1984, “A 'Bayesian' Exposition of Blackwell's Theorem on the Comparison of Experiments," in Bayesian Models of Economic Theory, ed by M. Boyer and R. E. Kihlstrom (Amsterdam: Elsevier).

Orosel, Gerhard O., 1996, "Informational Efficiency and Welfare in the Stock Market," European Economic Review, Vol. 40, pp. 1379-1411. 
Schlee, Edward E., 2001, "The Value of Information in Efficient Risk Sharing Arrangements," American Economic Review, Vol. 93, pp. 509-24.

Sulganik, Eyal, and Itzhak Zilcha, 1996, "The Value of Information in the Presence of Futures Markets," Journal of Futures Markets, Vol. 16, pp. 227-40. 